\title{
Online News Sites and Journalism 2.0: Reader Comments on Al Jazeera Arabic
}

\author{
Muhammad M. Abdul-Mageed
}

Department of Linguistics, Indiana University, Memorial Hall, 1021 E. Third Street, Bloomington, IN 47405, USA; mumageed@gmail.com

\begin{abstract}
The current paper investigates reader commenting on news sites as one facet of Journalism 2.0. Specifically, the themes, frequency, and regional coverage of readers' comments-and in general, their activity levels and distribution-are considered, with a goal to increase knowledge of convergent media and computer-mediated communication (CMC), as well as shed light on the interactivity strategies adopted by influential news producers. The corpus is collected from the Arabic news site of the controversial Middle East-based, bilingual network Al Jazeera. Reader commenting was found to be a regular occurrence on the site but distributed unevenly across stories. The stories focused mostly on themes related to military and political violence, politics, and foreign relations, and covered events related to the Arab world more than other regions. Also, patterns of commenting varied according to day of the week and position of the story on the web page. Overall, these findings suggest that citizen journalism—journalism as performed by lay persons—on Al Jazeera tends to be shaped by the coverage and layout of the news site. Moreover, citizen participation in online news sites such as Al Jazeera is still far from ideal, in that commenters are given neither the access nor the facilitation to use modalities other than written text. These limitations are critiqued in light of contemporary discourses about media convergence and Journalism 2.0.
\end{abstract}

Keywords: Journalism 2.0, computer-mediated communication, convergent media, Al Jazeera

Acknowledgement: The author is indebted to his advisor Prof. Susan C. Herring from the School of Library and Information Science, Indiana University, Bloomington, USA, for her useful comments on an earlier version of the current paper. All flaws, etc., however, remain exclusively the author's.

\section{Introduction}

ournalism 2.0 refers to the use of new technologies in collaborative news making and news analysis by lay persons with (minimal) web publishing skills, much as Web 2.0 refers to the use of similar technologies to foster user-generated content and user-to-user interaction. The version number in the term contrasts Journalism 2.0 with traditional journalism, where news collection, reporting, dissemination, and analysis were controlled by institutions. Journalism 2.0 fosters freer, more decentralized and more convergent journalistic practices and represents a second step toward more user-focused services. As part of this trend, online news sites strive to maintain a high degree of interactivity with their audiences by, e.g., facilitating site navigation, providing discussion forums, polls, and customizing to audiences' various surfing behaviors (Deuze, 2003).

One form of interactivity that some news sites employ is allowing readers to comment on published news reports. Such commenting represents a case of convergence between traditional media and new media, as well as a novel variety of asynchronous computermediated communication (CMC). However, little research exists about the phenomenon of reader commenting on news sites. Specifically, the themes, frequency, and regional coverage of readers' comments and in general, their activity levels and distribution - are unexplored areas. Studying reader comments has the potential to increase knowledge of convergent media and CMC, as well as shed light on the interactivity 
strategies adopted by influential news producers.

The goal of the current study is to investigate interactivity as embodied in readers' comments on top stories on the Arabic news site of Al Jazeera, the controversial Middle East-based, bilingual network. Al Jazeera is specifically interesting since it is one of the few media organizations that have started adopting some Journalism 2.0 facets, as allowing commenting on the stories. In addition, after the war on Iraq, Al Jazeera has been demonized by members of the Bush administration as well as some Arab and European government officials. Such being the case, and as a result of being a/the main source of news for most Arab and Middle East audiences, as well as a main source of world news along with other networks like the Cable News Network (CNN) and the British Broadcasting Corporation (BBC), Al Jazeera has attracted the attention of both audiences and researchers worldwide. In spite of this attention, most research on $\mathrm{Al}$ Jazeera to date has focused on the TV channel, rather than the news sites. In an attempt to bridge this gap, Abdul-Mageed and Herring (2008) analyzed some facets of both the Arabic and English language versions of Al Jazeera's news sites. No study to date, however, has focused on readers' comments as a readily accessible and an important facet of Al Jazeera. The present study focuses on interactivity on the site, and thus constitutes a second step in analyzing Al Jazeera's online presence. An underlying assumption of this study is that any attempt to get a grasp on Al Jazeera as an institution and a media organization should take comments, as a manifestation of Journalism 2.0, into account.

I analyze this phenomenon in a corpus of news reports and comments collected over a period of six weeks from Al Jazeera's Arabic news site at www.aljazeera.net. My primary research question is:

$R Q$ : To what extent is Al Jazeera Arabic's news site interactive?

More specifically, the study asks the following four questions:
1. What are the reports' themes and do they determine the frequency of commenting?

2. What are the regions covered by the reports and does they determine the frequency of commenting?

3. Is there a relationship between a report's position in the page and the frequency of comments on a report?

4. Does the frequency of commenting change depending on the day of the week?

Content analysis coding schemes were used to analyze the data. Reader commenting on Al Jazeera Arabic news stories was found to be a regular occurrence but distributed unevenly across stories. The stories focused mostly on themes related to military and political violence, politics, and foreign relations, and covered events related to the Arab world more than other regions. Also, the more frequent stories received more frequent comments.

\section{Background}

\subsection{Interactivity}

There are various definitions of interactivity in the literature, and these take into account three main distinctions: human-to-human interactivity, human-computer interactivity, and human-content interactivity. The current study is concerned with the first form where the focus is on human-to-human interactivity, or what can also be called interpersonal interactivity. One popular definition of interactivity, which considers this type of interpersonal interactivity, is that of Rafaeli (1988) and Rafaeli \& Sudweeks (1997), where interactivity is presented as "the extent to which messages in a sequence relate to each other and especially the extent to which later messages recount the relatedness of earlier messages" (Rafaeli and Sudweeks, 1997). Rafaeli (1988) makes a distinction between three types of communication: two way communication, reactive communication and fully interactive communication. According to Rafaeli, two-way communication occurs when messages are delivered both ways, reactive communication takes place when later messages respond to previous ones. Unlike 
these first two forms, fully interactive communication only occurs when later messages respond to a sequence of previous messages.

While Rafaeli's approach to the concept is interesting and useful, it does not fully capture the growing phenomenon of participatory journalism. Of direct relevance to the view of interactivity which will be adopted in the current study is Bordewijk and van Kaam's (1986) proposition that one crucial concept intimately related to interactivity is control. Bordewijk and van Kaam's' main interest is in revealing the control of information source and producer as well as the control of information time and choice of subject. Building upon this and other earlier propositions, Jensen (1998, p. 201) defines interactivity as the measure of a media's potential ability to allow users to exert an influence on the content and/or form of the mediated communication. Still, this definition is not completely satisfactory since it seems to prefer institutions who initiate the communication process to users. Given Jensen's definition, a communication situation in which users exert any influence, regardless of its extent or nature, on the content of the mediated communication would be labeled as interactive. This is no longer satisfactory in a Web 2.0 era where more freedom is granted to users and growing interest is underway in what the masses can produce. Interestingly, Stephen Fry defines Web 2.0 as referring to the reciprocity between the user and the provider, and a situation in which what is emphasized is such reciprocity. He describes the term as referring to an idea that is directly related to 'genuine' interactivity, simply because people can upload as well as download.

Thus, I choose to define interactivity as the degree to which users are granted access to act as co-producers of the content as well as form of the mediated communication. This definition seeks to widen the scope of the concept to incorporate all types of usergenerated as well as website-user generated content and form. Thus, whereas an online encyclopedia like Wikipedia is seen as very interactive in the sense that its content is user-generated, it is still not fully interactive when it comes to users' ability to collaborate in producing all aspects of the form. For a communicative situation to be fully interactive, users must co-produce the content as well as the form.

\subsection{Journalism 2.0}

Journalism 2.0 is one of the manifestations of the mother trend known as Web 2.0. The term Web 2.0 has been coined by O'Reilly Media in 2004 and since then several definitions have been proposed for the concept. Tim O'Reilly (2005) defines the term as follows:

"Web 2.0 is the network as platform, spanning all connected devices; Web 2.0 applications are those that make the most of the intrinsic advantages of that platform: delivering software as a continually-updated service that gets better the more people use it, consuming and remixing data from multiple sources, including individual users, while providing their own data and services in a form that allows remixing by others, creating network effects through an "architecture of participation," and going beyond the page metaphor of Web 1.0 to deliver rich user experiences."

Like Web 2.0 , Journalism 2.0 is a relatively new term. It employs the intrinsic advantages of the Web as a platform; adopts more userto-user interactivity; makes use of opensource software and pushes toward offering news organizations' content for free; downplays a news organization's power for the sake of gaining more audience; allows for more convergent news making in ways that contrast with traditional journalism's dependence on non-interactive, producerconsumer communication. Briggs (2007) explains how Journalism 2.0 makes use of email, instant messaging (IM), really simple syndication (RSS), and news alerts, etc. for news-making. He also explains how journalism can use services provided by social network sites (SNS) such as YouTube.com, Flicker.com, MySpace.com, and social bookmarking sites such as del.icio.us to interact with their audiences and/or create similar interactive platforms that belongs to their own organizations. Briggs 
(2007, p. 32) summarizes the spirit of Journalism 2.0 as follows: "Readers are no longer passive receivers of our messages. They create, share and comment. And they expect to do it on news Web sites, too."

But Journalism 2.0 is indeed nothing totally new: There has been a slow change from traditional, organization-based, producerconsumer journalism to more interactive, freer, and more democratic ways of doing the journalistic work. Different terms (e.g., online, participatory, open-source, citizen, and networked journalism, etc.) have been used to describe the move from traditional journalism to more modern journalisms, and I review these in the following lines with a focus on the concept of interactivity, since it is the concept of interactivity that has always been called for to reach an 'ideal' form of journalism.

Deuze (2003) identifies four types of online journalism: (1) mainstream news sites, (2) index and category sites, (3) meta- and comment sites, and (4) share and discussion sites. Deuze talks about three types of interactivity: navigational interactivity, functional interactivity and adaptive interactivity. Navigational interactivity, he maintains, allows users to navigate sites using, for example, buttons or scrolling menu bars. In functional interactivity users are allowed to share in the production of content via participating in bulletin board systems, moderated discussion lists, etc. Adaptive interactivity is related to the way sites customize to users' surfing behaviors, remember their preferences, etc. Deuze holds that mainstream news sites, at the time he conducted his study, mainly employed navigational interactivity and that they did not differ much from print journalism and its approach to journalistic storytelling, news values, and relationships with audiences.

Schultz (1999) investigated interactive features in 100 U.S. newspapers online and found that while 94 percent of the newspapers provided at least one e-mail address to the newsroom, 67 percent of the newspapers did not provide direct e-mail links from the stories to the authors. Also, chat rooms were rarely provided and about one fourth of the sample provided online polls or surveys. In addition, only 33 percent ran discussion forums, and letters to the editor were used less often than might be expected. Schultz thus concludes that these online newspapers are far from interactive.

Similarly, Schultz (2000) studied interactivity via reader e-mail and online forums for The New York Times. It was found that most journalists evaluated e-mail communication with readers in positive terms. Also, the average number of e-mails sent to such journalists by readers was found to be manageable, and journalists responded to emails in various ways. Schultz also found that participation in the forum postings ranged from 1 to 1500 postings over a period of 10 months, with a misleadingly' high mean of 89 postings. The mean is misleading in that certain participants sometimes dominated the discussions. Forum discussions were also found to be extended to e-mail threads between certain participants. Again, Schultz concludes that only a special stratum of readers was active and writes letters to the editor or posts comments to online forums.

Chung (2004) studied whether and how interactive features were used by news organizations by conducting a content analysis of the 43 websites which were nominated in September 2002 for the Online Journalism Awards by the Online News Association. She used a six-dimensional model of interactivity that incorporated the dimensions of audience control, exchange, speed, information collection, personalization and sensory engagement and found that the human interactivity dimension of 'exchange' was used 'far less' than the medium or medium-human interactivity dimensions. Chung also conducted interviews with the websites producers about why such interactive features were used or not. She also explored in her interviews the site producers' perception of interactivity, the role of the journalist and audience, and the future of news in the digital age. It was found that although site producers were generally interested in interactive features, they were cautious about using them. In addition, it was found that while site producers agreed that there was an increased role for the audience, they did not believe that the role of the journalist or the definition of the news has changed. Chung concludes that the traditional one-way, top-down culture of centralized 
news production was still 'going strong,' and hence there was still a resilience of the traditional paradigm of mass communication.

In spite of this 'resilience' of the traditional paradigm of mass communication, the Internet has undoubtedly revolutionized news making and changed the face of journalism. Readers currently have more immediate, nonlinear (Rich, 2003), and more customized type of news. Newsmakers have found in the Internet a means to extend their reach to more and more masses and, thus, more and more people are using online news sites as their (sometimes exclusive) source of news. Since readers are becoming more active participants, and more involved in the process of news making, the traditional influence of newsmakers is being increasingly challenged by a growing interest in the voices of the masses. Readers are to varying degrees changing from mere consumers to coproducers of content and we are moving toward open source (Deuze, 2001) participatory (Bowman and Willis, 2002; Deuze et al., 2007), Networked (Jarvis, 2006), etc., journalism. Jarvis (2006) explicates this form of journalism as follows:

"IIt] takes into account the collaborative nature of journalism now: professionals and amateurs working together to get the real story, linking to each other across brands and old boundaries to share facts, questions, answers, ideas, perspectives. It recognizes the complex relationships that will make news. And it focuses on the process more than the product."

\subsection{Al Jazeera}

One common element perhaps in all of what has been written about Al Jazeera is that it attracted much attention and, for better or worse, achieved some good degree of success. "All this trouble from a matchbox like this," the Egyptian president, Hosni Mubarak, once exclaimed when he arrived to take a look at Al Jazeera's headquarters in Qatar (Whitaker, 2003). Mubarak's comment is reflective of the controversiality of Al Jazeera. Since the channel was launched in late 1996, it has been creating 'troubles' by fostering hot debates on various issues that were considered previously taboos. 'The opinion, and the other opinion' approach and motto of the network was new in the Arab world when the network was launched. Not until Al Jazeera broadcast video statements by bin Laden and other Al-Qaeda leaders did Al Jazeera stir the wrath of the U.S. Al Jazeera's coverage of the War on Afghanistan and Iraq has been a source of trouble to the U.S. Indeed, the war on Iraq was seen as marking an end to the 'hegemony' of Western media (Seib, 2005).

Research on Al Jazeera so far has focused on three main areas: first, describing it and its effect both on the Middle East and globally, second, contrasting it to other media organizations, and, third, comparing its Arabic and English Websites. Ghareeb (2000) falls in the first category. He describes the historical context of Al Jazeera's rise and its effect on the Arab world and its politics. Ghareeb lists a number of the criticisms hurled at Al Jazeera and discusses them. He introduces Al Jazeera within the wider context of other media institutions in the Arab world.

Barkho (2006), as an example of the second thread of research mentioned above, compared the Middle East-related stories from the Arabic version of Al Jazeera website to the Arabic versions of the websites of the $\mathrm{BBC}$ and the CNN. An attempt was also made to see how the two channels, the BBC and the $\mathrm{CNN}$, tried to render into English and interpret the culture specific language used by $\mathrm{Al}$ Jazeera broadcasters. Leon concludes by attributing the success of $\mathrm{Al}$ Jazeera to the way it shows 'respect' for religion, culture, tradition and the aspirations of its audience. Leon adds that Al Jazeera's competitors, like the CNN and the BBC, 'sorely' fail to show similar 'respect' to these.

Abdul-Mageed and Herring (2008) compared the Arabic and English language versions of Al Jazeera in terms of their layouts and the structural features, regional and thematic coverage, and ideological perspective reflected in the headlines of news reports. The content analysis they employed revealed differences between the two versions for all aspects except for thematic coverage. In addition, Abdul-Mageed and Herring, as a result of employing a critical discourse analysis of the headlines, found 
some subtle systematic biases in coverage, alongside efforts to present ideological balance.

Other research on Al Jazeera has focused on the frequency of its web news updates (Kutz and Herring, 2005), the frames it used during the Iraq war (Dimitrova and ConnollyAhern, 2007), and the demographics and psychographics of its audience (Auter et al., 2004).

Readers' comments on Al Jazeera's online news stories constitute one facet of Journalism 2.0 that makes it possible for $\mathrm{Al}$ Jazeera's readers to have access not only to the stories produced by Al Jazeera's staff, but to the final product embodied in the amalgam of such stories as well as the comments on them. In this way, the value as well as the effect of Al Jazeera's final product is an aggregate of the values and effects of the stories as well as the comments. By allowing readers to comment on the stories, Al Jazeera became one of the few organizations that have taken what Briggs $(22007$, p. 32) calls the 'next step' in Journalism 2.0.

\section{Methodology}

\subsection{Data Sampling and Collection}

The data for this study are top stories and comments on such stories collected from the Arabic Al Jazeera news site (http://ww.aljazeera.net/News/). On that site, the top stories and comments on them are delivered exclusively in Arabic. During the time of collection the site typically had 9 top reports. Each report was dealt with as having one story, and the two terms report and story will henceforth be used interchangeably unless otherwise indicated. The first story is given priority in the page: it is typically accompanied by a large picture and is displayed in the middle of the upper part of the page. Also, this first story is typically accompanied by a blurb in the news page. The rest of the stories are arranged in two columns, and each of them is accompanied by a picture smaller than that accompanying the first picture. Additionally, none of this last group of stories is accompanied by a blurb in the news page.

In order to access the text of any of the top stories a reader clicks on either the picture or the headline of the story. Clicking on the hyperlink leads the reader to a new page containing the whole text of the story. Below the text of each story, readers are invited to comment on the story, typically, via a phrase worded as "your comment on the topic." During the collection period it was not required that readers subscribe or register to the website before they could comment. A reader was only required to fill in his/her name, e-mail, and address. The text was then filled in a box and a reader clicked on a 'submit' button to post the comment. Importantly, names, e-mails, and addresses are obligatory fields. For the address field, readers usually just give their country or city names in any language (though readers usually use Arabic and/or English). A comment itself, however, must be in Arabic, as the guidelines for the comments indicate. Such guidelines would appear, in a screentips fashion, as soon as a user hovers over the commenting box. The guidelines are brief descriptions of what users should, and should not, do.

Significantly, during the time of collection no instructions were given to readers regarding the content of the comments and nothing about filtering such contents was stated on the news site. The comments are typically arranged directly below each story. If the number of comments exceeds 15, the site managers arrange these comments in pages accessible via hyperlinked numbers in revered chronological order (i.e., the most recent comment is given in the page labeled ' 1 ', and the earliest comment is given the page with the largest number.) The hyperlinked numbers via which the comments are accessed are given on the bottommost part of each story's page. Each time a reader accesses a new set of comments the story is typically shown first and a set of 50 comments are shown below it. So long as a story is still occupying a position in the main page of the news, it is open to commenting. As soon as the story is removed from the news page, it is archived and readers cannot comment on it.

Thus, the 9 top stories, along with the comments on each story, were collected every other day over a period of 6 weeks, from September $3^{\text {rd }}$ to October $13^{\text {th }}, 2007$. The total number of stories thus totaled 189 , and 
the total number of comments was 5219. In order to guarantee collecting all the comments on a given story, the stories were collected only after they had been archived and were no longer accessible for commenting. Since no links to archived stories were provided on the Al Jazeera site, I saved the news pages containing the links to the top stories every other day and then accessed these stories along with their comments later via such links. Since I collected 6 weeks' reports every other day, I ended up with 3 weeks' reports, with each day of the week represented equally.

\subsection{Analytical Methods}

Web content analysis (Bauer, 2000; Herring, 2004; 2008b) was employed to identify interactivity in the comments on the news stories. The number of comments on each separate story was counted. To get the average number of comments per day the comments on all the stories of each separate day were counted. To identify whether there is a relationship between a story's position in the news page and the number of comments, and hence the interest readers show in a story, the number of comments on all the stories occurring on the same position on the news page was counted. The correlation between the number of comments on stories and different days of the week was spotted by dividing the corpus into seven sub-corpora each of which was composed of three occurrences of the same day of the week (i.e., three Mondays, three Tuesdays, etc.). Thus, the comments on each of these sub-corpora were counted.
The stories were then coded for regional coverage using the coding scheme developed by Abdul-Mageed and Herring (2008) which is composed of two main categories: Arab and non-Arab. The second category, non-Arab, is divided into four different subcategories: first world, second world, third world, and Muslim. The number of comments on the stories belonging to each of these categories, and sub-categories, was counted. Thematic categories of the news stories were identified by coding these stories using a model adapted from van Dijk (1988). A bottom-up approach was followed to adapt van Dijk's model. The adapted model included the following categories: politics; foreign relations/affairs; economics; military and political violence; religion and culture; disaster; and other. The number of comments on each of these categories was also counted to identify any correlations/relationships between the categories of the news stories and comment frequencies. Table 1 below shows how the coding scheme was operationalized, and exemplifies each category.

Since I employed the two coding schemes used here in an earlier study (Abdul-Mageed and Herring, 2008) with an inter-rater reliability of $98 \%$, I only employed intra-rater reliability for the current study. I coded $15 \%$ of the data and after six months re-coded the same data. Intra-rater reliability exceeded $99 \%$. I also coded the rest of the data. 


\begin{tabular}{|c|c|c|}
\hline Code & Operationalization & Example \\
\hline Politics & $\begin{array}{l}\text { Stories that focus on political issues } \\
\text { within one country or a political issue } \\
\text { that is offered without a focus on } \\
\text { international diplomacy }\end{array}$ & $\begin{array}{l}\text { - Musharaf Announces he will Quit as Army } \\
\text { Chief, and Court Battles him (Mon., Sept. } \\
17^{\text {th }}, 2007 \text { ) } \\
\text { - Lebanon Withholds Breath before } \\
\text { Presidential Election Session (Tues., Sept. } \\
17^{\text {th }}, 2007 \text { ) }\end{array}$ \\
\hline $\begin{array}{l}\text { Military and } \\
\text { political } \\
\text { violence }\end{array}$ & $\begin{array}{l}\text { Stories that involve war between two } \\
\text { or more countries as well as political } \\
\text { violence within one country, whether } \\
\text { the latter involves a disciplinary army, } \\
\text { guerrillas, political parties, or } \\
\text { opposition groups }\end{array}$ & $\begin{array}{l}\text { - Tens of Talibanis Killed in US Raid South } \\
\left.\text { Afghanistan (Thurs, Sept. } 13^{\text {th }}, 2007\right) \\
\text { - Israeli Enters South Gaza and [Islamic] } \\
\text { Jihad warns against Breaking into the } \\
\text { District (Sat., Sept. } 15^{\text {th }}, 2007 \text { ) }\end{array}$ \\
\hline $\begin{array}{l}\text { Foreign } \\
\text { affairs }\end{array}$ & $\begin{array}{l}\text { Stories that focused on international } \\
\text { diplomacy involving two or more } \\
\text { countries }\end{array}$ & $\begin{array}{l}\text { - Rohani in Berlin and Cairo Opposes } \\
\text { Military Action against Tehran (Wed., Sept. } \\
19^{\text {th }}, 2007 \text { ) } \\
\text { - Rice Praises French Co-operation with the } \\
\text { US (Tues., Sept. } 25^{\text {th }}, 2007 \text { ) }\end{array}$ \\
\hline Disaster & $\begin{array}{l}\text { Stories that dealt with natural or } \\
\text { human-made hazards (i.e., those } \\
\text { resulting from negligence, errors, } \\
\text { etc.) impacting communities/societies } \\
\text { and/or environment }\end{array}$ & $\begin{array}{l}\text { - Hurricane Strongly Hits Chinese East } \\
\text { Coast (Wed., Sept. 19 }{ }^{\text {th }}, 2007 \text { ) } \\
\text { - Number Yemeni Military's Victims of } \\
\text { Volcanic Eruption Rise to } 8 \text { (Mon., Oct. } 1^{\text {st }} \text {, } \\
\text { 2007) }\end{array}$ \\
\hline $\begin{array}{l}\text { Religion } \\
\text { and culture }\end{array}$ & $\begin{array}{l}\text { Stories that highlighted sets of tenets } \\
\text { as well as symbolic structures and } \\
\text { human practices (including art and } \\
\text { media activities) clustering around } \\
\text { them. }\end{array}$ & $\begin{array}{l}\text { - Ramadan on Al-Jazeera Documentary: A } \\
\text { Meeting Point of Knowledge and } \\
\left.\text { Entertainment (Tues. Sept. } 11^{\text {th }}, 2007\right) \\
\text { - Egyptian Endowments Minister's Call for } \\
\text { Visiting Al-Aqsa supported by a Majority } \\
\left.\text { (Fri., Oct. } 5^{\text {th }}, 2007\right)\end{array}$ \\
\hline Economics & $\begin{array}{l}\text { Stories that involved the production, } \\
\text { distribution, and/or consumption of } \\
\text { goods within one or more countries. }\end{array}$ & $\begin{array}{l}\text { - European Court Upholds Indictment of } \\
\text { Microsoft (Mon., Sept. } 17^{\text {th }}, 2007 \text { ) } \\
\text { - People's Fortunes Lost in Iraq Due to War } \\
\text { (Mon., Sept. } 15^{\text {th }}, 2007 \text { ) }\end{array}$ \\
\hline
\end{tabular}

Table 1: Coding scheme for thematic coverage

\section{Findings}

\subsection{Days of the Week}

The current study aimed at answering the following research question: "To what extent is Al Jazeera Arabic news site interactive in terms of commenting?" The findings of the content analysis, which I present in the current section, answer this question of the study. As stated earlier, the total number of reports in the corpus was 189 and the total number of comments on these reports was
5219. The average number of comments per day was thus 248.52 and the average number of comments per report was 27.61. As is shown in figure 1 , the rate of comments changed from one day to another, but comments tended to be higher in certain days. As table 2 shows, comments were specifically higher on Sundays. In fact, comments occurring on Sundays were one fourth of the whole number of comments. Comments on Thursdays also constituted $18 \%$ of the data. Fridays were third in frequency of comments, with $12 \%$ of all the comments in the corpus. 


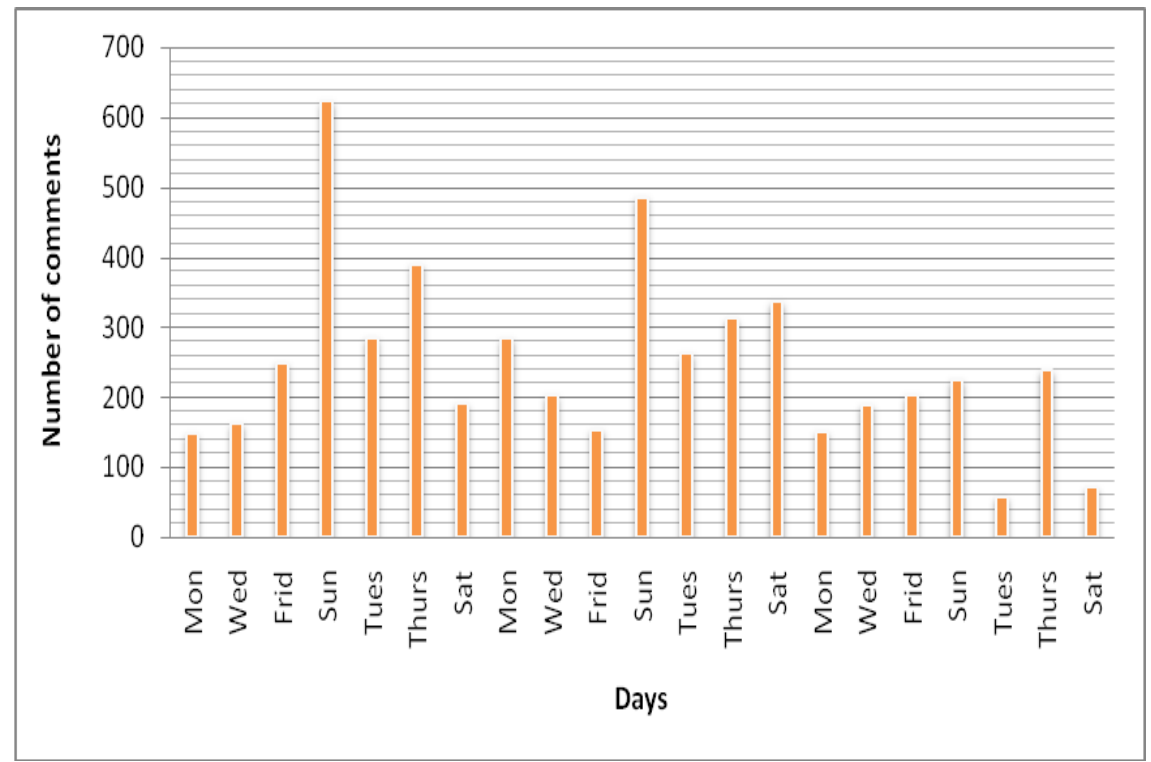

Figure 1: Variation of comments per days

\begin{tabular}{lllllllll}
\hline & Sundays & Thursdays & Fridays & Tuesdays & Saturdays & Mondays & Wednesdays & All \\
\hline Total & 1334 & 940 & 606 & 605 & 598 & 582 & 554 & 5219 \\
Average & 444.66 & 313.33 & 202 & 201.66 & 199.33 & 194 & 184.66 & 248.52 \\
\hline
\end{tabular}

Table 2: Distribution of comments by day of the week

\subsection{Position of Story}

Figure 2 below shows a screenshot of the layout of the news page, with story positions indicated. As table 3 below also shows, not all stories received the same number of comments. A relationship was found between the position of a story in the main page of the news and the number of comments such a story receives. The topmost story received the greater number of comments. The 21 topmost stories in the 21 days received a total of 858 comments, with an average of 40.85 comments per story. The topmost story in all collection days thus made up about $16 \%$ of the whole number of comments in the corpus.

Furthermore, comments tended to decrease as the position of a story became less salient in the main news page. This is typically true for most of the stories, but there are exceptions: As we go to the bottom of the two columns, comments tended to increase again. This is true for stories number 7 and 8 . Figure 3 below shows the relationship between a story's position and frequency of commenting. (In figure 3, story 1 stands for position 1 , story 2 for position 2 , etc.). 


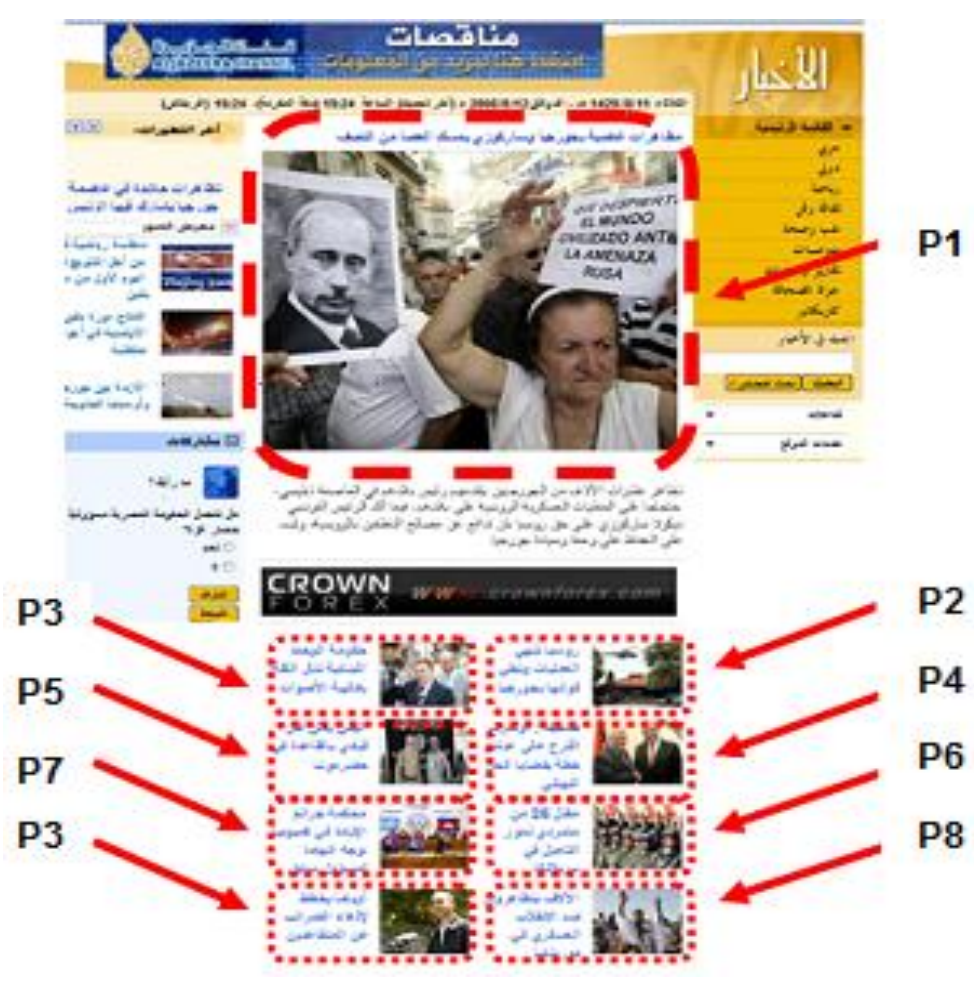

Figure 2: A screenshot of Al Jazeera Arabic's news page

\begin{tabular}{llllllllll}
\hline & P 1 & P2 & P 3 & P 4 & P 5 & P 6 & P 7 & P 8 & P 9 \\
\hline Total & 858 & 727 & 671 & 589 & 667 & 411 & 454 & 513 & 329 \\
Average & 40.85 & 34.61 & 31.95 & 28.04 & 31.76 & 19.57 & 21.61 & 24.42 & 15.66 \\
Range & $3-192$ & $0-97$ & $0-181$ & $0-259$ & $0-153$ & $0-101$ & $0-102$ & $0-102$ & $0-56$ \\
Percent & $16.44 \%$ & $13.93 \%$ & $12.86 \%$ & $11.29 \%$ & $12.78 \%$ & $7.88 \%$ & $8.70 \%$ & $9.83 \%$ & $6.30 \%$ \\
\hline
\end{tabular}

Table 3: Distribution of comments by story position (P)

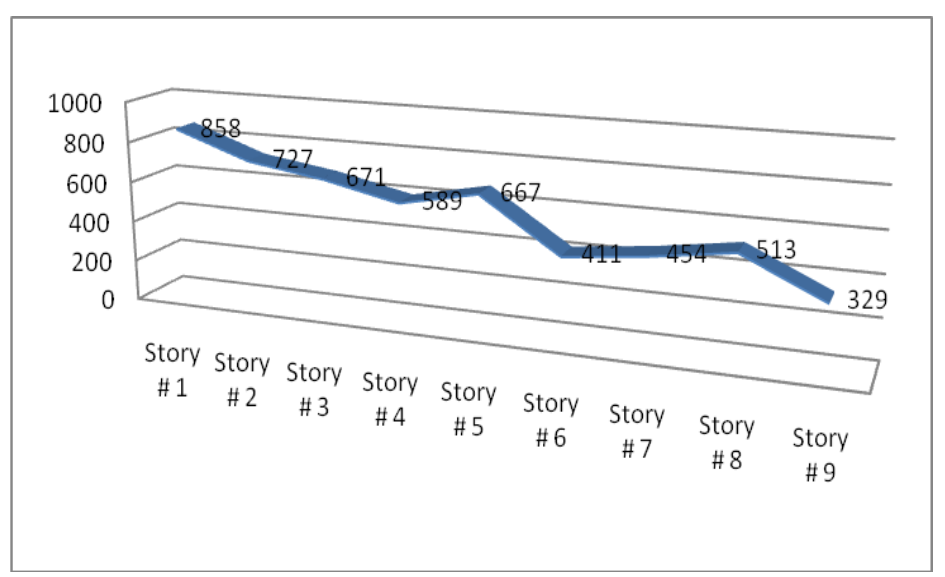

Figure 3: Relationship between story position and frequency of comments 


\begin{tabular}{lcllr}
\hline & Position 1 & $\begin{array}{l}\text { Right-hand column positions } \\
(\text { P2, P4, P6 \& P8) }\end{array}$ & $\begin{array}{l}\text { Left-hand column positions } \\
(\text { P3, P5, P7 \& P9) }\end{array}$ & All \\
\hline Total & 858 & 2240 & 2121 & 521 \\
Percent & 16 & 43 & 41 & 9 \\
\hline
\end{tabular}

Table 4: Distribution of comments by Positions (P1, right-hand positions \& left-hand positions)

In addition, as table 4 shows, stories that were presented in the right hand column in the main news page, received very slightly more comments than those presented on the left hand column.

\subsection{Thematic Coverage}

Each story was also coded for the thematic category of the topic it covers. Figure 4 below shows the percentage of each type of news categories as found in the corpus. About $88 \%$ of the stories were about 'politics,' 'military' and political violence,' and 'foreign relations' (i.e., relationships between two or more countries). As figure 4 shows, politics was the first frequently occurring category, with $34 \%$; military and political violence was second in frequency, with $30 \%$; and foreign relations was the third category, with $24 \%$ of the stories. Religion and culture was the fourth category, with $4 \%$ of the stories. The remaining $8 \%$ of the stories was shared by the categories of economics, disaster, and other.

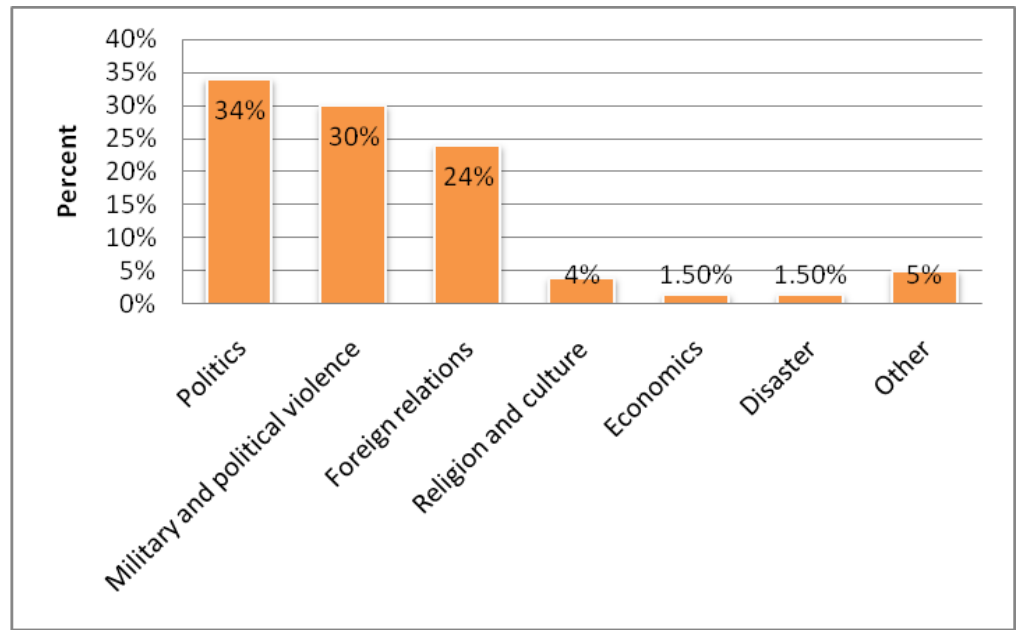

Figure 4: Percents of thematic categories of stories

As shown in table 5 below, in about half of the collection period ( $n=10$ out of 21 days) the first story covered 'military and political violence.' 'Politics' and 'foreign relations' had almost equal shares of showing up in the first story position. Table 5 also shows that whereas the frequency of 'political,' 'foreign relations' and 'military and political violence' stories decreased, as the story position became less salient, all other news categories tended to increase toward the bottom part of the news page. Stories related to the category of Religion and Culture, which was the fourth most frequent category, were provided in low positions in the news page, i.e., positions 8 and 9. Table 6 offers keys to the news categories abbreviated in table 5 . 


\begin{tabular}{|l|l|l|l|l|l|l|l|}
\hline Category & $\mathrm{P}$ & $\mathrm{MP}$ & $\mathrm{FR}$ & $\mathrm{RC}$ & $\mathrm{E}$ & $\mathrm{D}$ & $\mathrm{O}$ \\
\hline Story 1 & 5 & 10 & 6 & 0 & 0 & 0 & 0 \\
\hline Story 2 & 10 & 8 & 3 & 0 & 0 & 0 & 0 \\
\hline Story 3 & 5 & 8 & 7 & 0 & 0 & 0 & 1 \\
\hline Story 4 & 5 & 8 & 7 & 0 & 0 & 1 & 1 \\
\hline Story 5 & 10 & 7 & 3 & 0 & 0 & 0 & 0 \\
\hline Story 6 & 7 & 9 & 5 & 0 & 0 & 0 & 0 \\
\hline Story 7 & 9 & 3 & 7 & 0 & 0 & 1 & 2 \\
\hline Story 8 & 8 & 1 & 5 & 2 & 3 & 0 & 1 \\
\hline Story 9 & 5 & 3 & 2 & 6 & 0 & 1 & 4 \\
\hline Total & 64 & 57 & 45 & 8 & 3 & 3 & 9 \\
\hline
\end{tabular}

Table 5: Distribution of news categories by story position

\begin{tabular}{ll}
\hline Code & Abbreviation \\
\hline Politics & $\mathrm{P}$ \\
Military and political violence & $\mathrm{MP}$ \\
Foreign relations & $\mathrm{FR}$ \\
Disaster & $\mathrm{D}$ \\
Religion and culture & $\mathrm{RC}$ \\
Economics & $\mathrm{E}$ \\
Other & $\mathrm{O}$ \\
\hline
\end{tabular}

Table 6: Key to codes used in Table 4

As a footnote, the main news page of $\mathrm{Al}$ Jazeera has a secondary area where more stories are offered. Typically these are offered under a number of titles: Arabic, International, Economic, Reports and Discussions, Medicine and Health, Varieties, Culture and Art, Sports, and Press Tour. Since these were not part of the data collected for the current study, I cannot tell to what extent readers were, or were not, interested in commenting on 'non-top' stories in such a secondary area. It seems that the 'more significant' and 'hotter' news stories are offered as top stories, whereas others (e.g., police and crime, sports, social affairs, etc.) are rarely presented as belonging to that category. I believe that this practice on the part of Al Jazeera is not due to a lack of interest in this type of story. Rather, the turbulent situation in the Middle East seems to impose the practice of prioritizing a certain type of news categories. Additionally, it may also be the case that Al Jazeera is attempting to satisfy the needs of its community of interest (Herring, 2008) by prioritizing such stories.

I now turn to the patterns of commenting, in an attempt to identify which types of news categories Al Jazeera grassroots are interested in. It was found that the stories that were most frequent on the site received more comments than other less frequently occurring stories. Table 7 shows the frequencies and percents of stories as well as corresponding comments. The table shows that Political stories received $32 \%$ of the comments, and were first in frequency. The second most frequently occurring category of comments was that of military and political violence (percent=31), and foreign relations was the third, with $27 \%$. The categories of disaster, economics, religion and culture, and other received fewer comments. Figure 5 below shows the correspondence between the thematic coverage of stories and comments. 


\begin{tabular}{llllllllll}
\hline & & Politics & $\begin{array}{l}\text { Military and } \\
\text { political } \\
\text { violence }\end{array}$ & $\begin{array}{l}\text { Foreign } \\
\text { relations }\end{array}$ & Disaster & $\begin{array}{l}\text { Religion } \\
\text { and } \\
\text { culture }\end{array}$ & Economics & Other & Total \\
\hline \multirow{2}{*}{ Stories } & Number & 64 & 57 & 45 & 3 & 8 & 3 & 9 & 189 \\
& Percent & $34 \%$ & $30 \%$ & $24 \%$ & 1.5 & $4 \%$ & 1.5 & $5 \%$ & $100 \%$ \\
\multirow{2}{*}{ Comments } & Number & 1679 & 1597 & 1395 & 121 & 154 & 16 & 257 & 5219 \\
& Percent & $32 \%$ & $31 \%$ & $27 \%$ & $2 \%$ & $3 \%$ & $0.00 \%$ & $5 \%$ & $100 \%$ \\
\hline
\end{tabular}

Table 7: Correspondence stories' themes and comments received

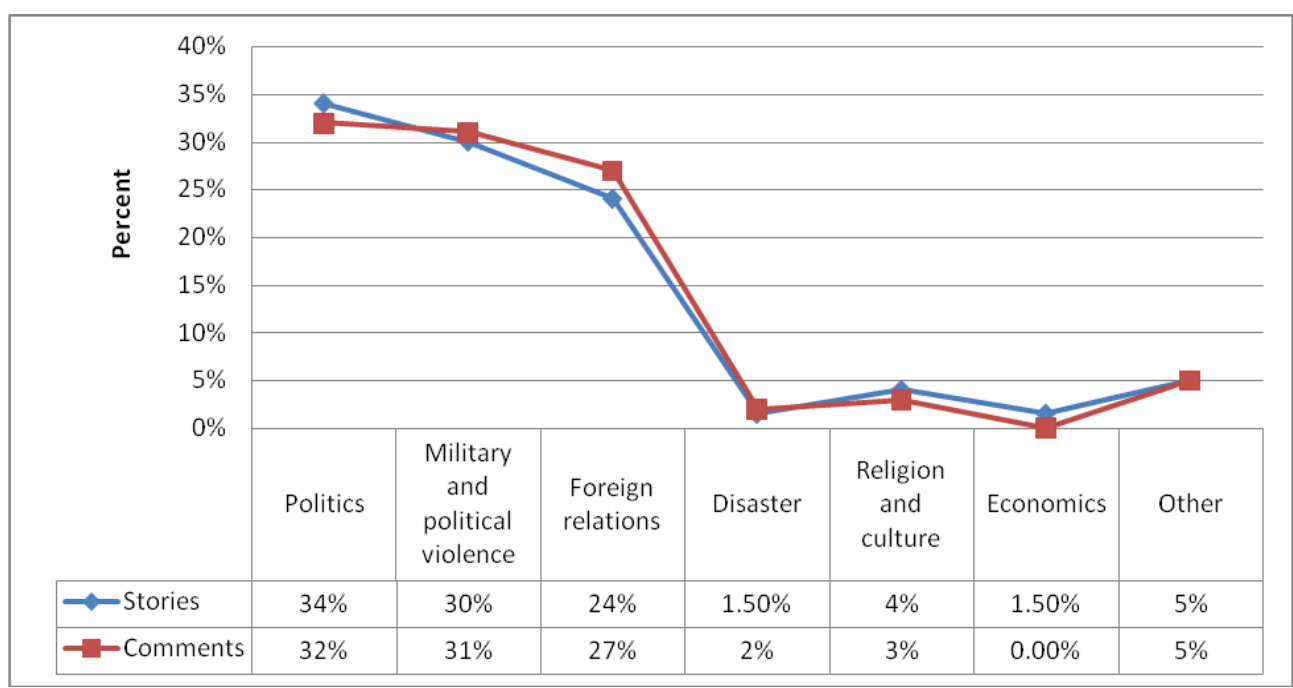

Figure 5: Percents of thematic categories of stories and received comments

\subsection{Regional Coverage}

The results of the analysis of regional coverage show that $62 \%$ of the stories covered the Arab world, whereas $38 \%$ covered the non-Arab countries. Of the $38 \%$ of non-Arab countries the second world occupied $51 \%$, the first world $29 \%$, and the third world $20 \%$. The more frequent stories received more frequent comments: Stories related to the Arab world received $73 \%$ of the comments, whereas second world's stories received $14 \%$ of the comments. Also, first world's stories received $10 \%$ of the comments and third world's stories received $3 \%$. Table 8 below shows numbers and percents of the stories as well as the comments. The relationship between the frequencies of stories and comments is shown in figure 6 below.

\begin{tabular}{|c|c|c|c|c|c|c|}
\hline & & Arab world & 1st world & 2nd world & 3rd world & Total \\
\hline & Number & 117 & 21 & 37 & 14 & 189 \\
\hline \multirow[t]{2}{*}{ Stories } & Percent & $62 \%$ & $11 \%$ & $20 \%$ & $7 \%$ & $100 \%$ \\
\hline & Number & 3798 & 535 & 721 & 165 & 5219 \\
\hline Comments & Percent & $73 \%$ & $10 \%$ & $14 \%$ & $3 \%$ & $100 \%$ \\
\hline
\end{tabular}




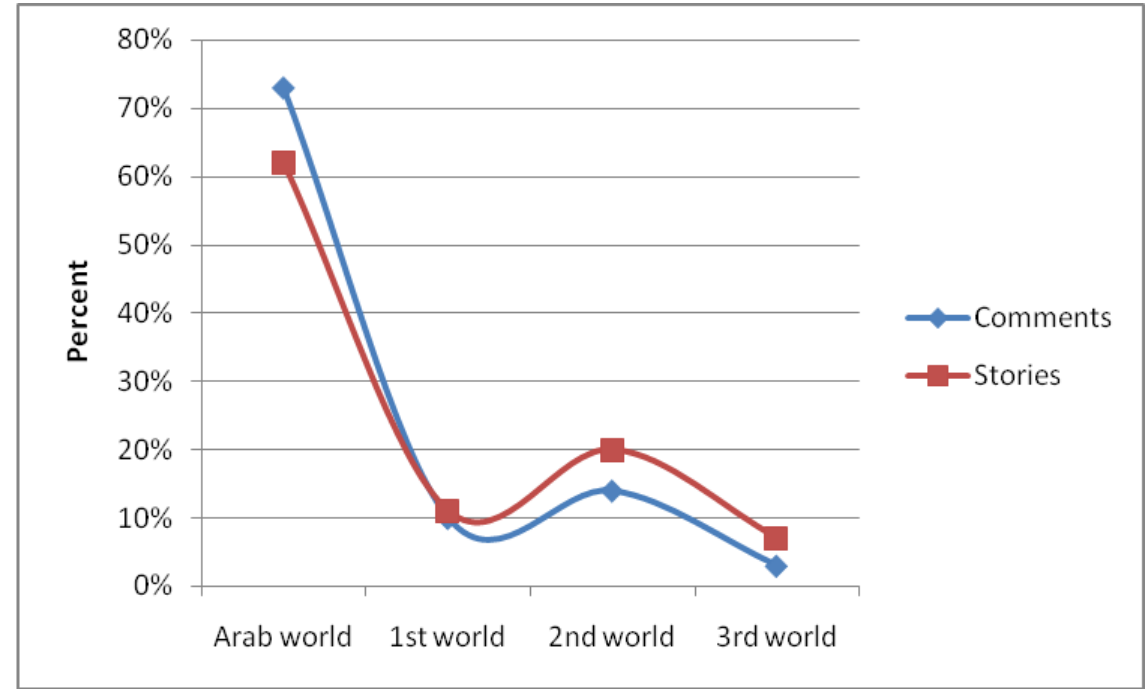

Figure 6. Story-comment correspondence of Arab, 1 st, $2^{\text {nd }}$, and 3rd worlds

In addition, table 9 below also shows that the non-Arab non-Muslim world received $22 \%$ percent of the coverage of the stories and that the non-Arab Muslim world received $16 \%$ of the regional coverage. Again, the frequency of commenting was similar to that of stories in terms of regional coverage in that the non-
Arab non-Muslim world received more comments (percent=15) than the non-Arab Muslim world (percent=12). Figure 7 shows this relationship between frequencies of stories and comments as to the Arab, nonArab Muslim, and non-Arab non-Muslim worlds.

\begin{tabular}{|l|l|l|l|l|l|}
\hline & & Arab world & Non-Arab Muslim world & Non-Arab non-Muslim world & Total \\
\hline \multirow{4}{*}{ Stories } & Number & 117 & 31 & 41 & 189 \\
\cline { 2 - 6 } & Percent & $62 \%$ & $16 \%$ & $22 \%$ & $100 \%$ \\
\hline \multirow{3}{*}{ Comments } & Number & 3798 & 648 & 773 & 5219 \\
\cline { 2 - 6 } & Percent & $73 \%$ & $12 \%$ & $15 \%$ & $100 \%$ \\
\hline
\end{tabular}

Table 9: Frequencies of stories and comments of Arab, non-Arab Muslim and non-Arab nonMuslim worlds

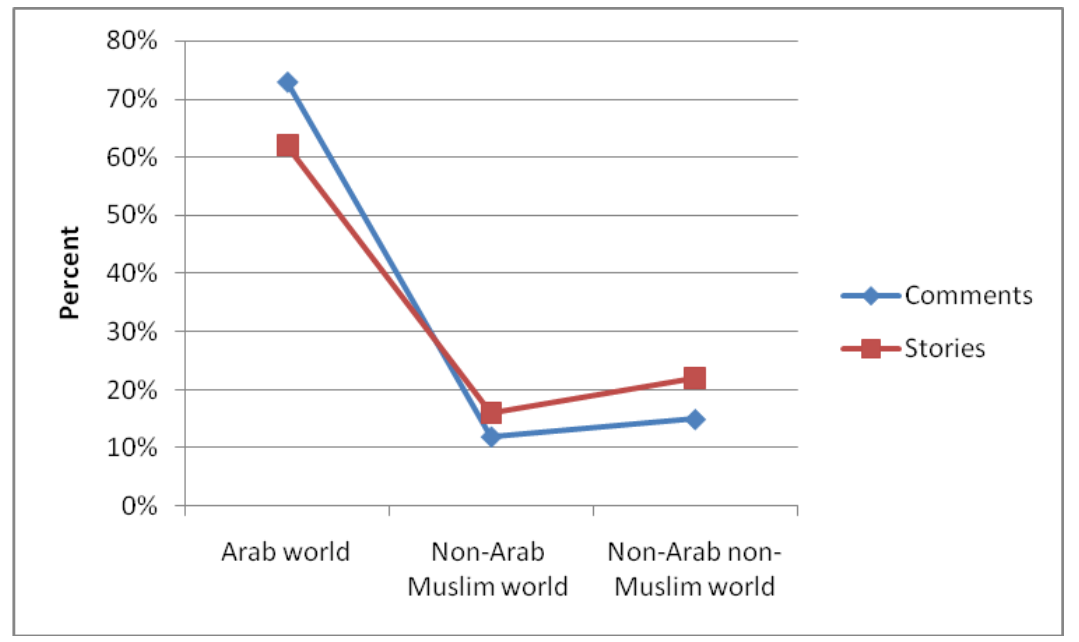

Figure 7: Story-comment relationship of Arab, non-Arab Muslim and non-Arab non-Muslim worlds 


\section{Discussion}

\subsection{Days of the Week}

Whether the average rate of comments per story, 27.61, is high or not remains an open question, since, to the best of my knowledge, there are no currently available comparative research findings. However, it seems that $\mathrm{Al}$ Jazeera has an active sphere. The finding that rates of comments on Sundays were high, with $25.50 \%$ of all the comments in the corpus, may be due to a change in the rates of comments related to readers outside the Arab world: Sunday is a working day in many Arab countries, and it seems that readers in America, Europe and other places outside the Arab world were more active commenters especially on Sundays, when they are in their weekends. This becomes plausible when it is taken into account that readers from the Arab world continue to comment on Sundays, during their work hours. Perhaps commenting rates also increased on Thursdays since the following day, Friday, is not a working day in the Arab world. It thus seems that commenters in the Arab world became more active as an anticipation of the weekends.

\subsection{Position of Story}

Given the fact that the topmost story was usually a story that hits the hottest issue from the point of view of Al Jazeera and was typically accompanied by the biggest image as well as a blurb in the main news page (as stated above, this was the only story accompanied by a blurb in the main news page), the top story was more salient than others. Additionally, the first story was offered on the upper part of the page and thus readers did not have to exert the extra efforts of scrolling down in order to read and hence comment on it. Such an importance, salience, as well as the less required efforts on the part of readers who want to comment may account for the frequency of comments on stories that occurred in position 1.

The finding that comments tended to decrease as the position of a story became less salient in the main news page may be due to that commenters tended to assign some salience to the last-occurring stories.
This can be interpreted with the belief held by some scholars that what occurs last is remembered by readers, and thus such final stories have some 'end-focus' (see e.g. Murphy et al., 2006). Furthermore, stories on the right hand column in the main news page received very slightly more comments than those presented on the left hand column probably because Arabic, the language in which the corpus was written, is read and written from right to left. This last finding perhaps also shows that commenters did not have strikingly different preferences as to proceeding vertically or horizontally from one more salient position to a less salient one as to all stories except those in positions 1, 2 and 3.

\subsection{Thematic Coverage}

The finding that about $88 \%$ of the stories were about 'politics,' 'military' and political violence,' and 'foreign relations' is perhaps due both to the nature of the situation in the Middle East, the focus of the networks' regional coverage: The Middle East is experiencing a continuing war in Iraq, fighting between the Israeli forces and Palestinian fighters, turbulent (and sometimes bloody) political and civil scene in Lebanon, etc. Further, changes in world politics after $9 / 11^{\text {th }}$ impacted the Middle East, probably more than other areas, mainly because of the war on Iraq but also because of the emerging role of Iran as a local force in the Middle East that is becoming increasingly seen as a threat to 'peace' in the Middle East as well as the rest of the world by Israel, some Arab as well as Western countries. Such being the scene in the Middle East, it is expectable to have Al Jazeera's news site focus on the three abovementioned thematic categories.

The finding that there was a strong correspondence between the frequencies of stories' themes and comments received by each type of story theme may be explained by two factors: Middle Eastern and world politics after $9 / 11^{\text {th }}$ as well as Al Jazeera's news site design and the arrangement of news stories in it. As for the political aspect, again, the Arab world especially and the Middle East generally is a region of political unrest and nascent democracies. More often than not the peoples 
in countries belonging to this region are struggling for their freedom of expression and fighting against what they see as injustices. It is indeed the case that people in this region are forced to be more or less involved in politics, in the general sense of the term. This is due to several reasons.

First, the terrorist attacks of 9/11, 2001 have brought this area and its people into a focus and the people there feel that, for better or for worse, there is a growing interest in them and in what they think and stand for.

Second, the Bush administration, indeed for a few months, has been pushing for 'democratizing' this region via creating what has been labeled 'The Big Middle East." A number of governing parties oppose this practice of the US (perhaps since it would have demolished their 'thrones') and the peoples of such countries had mixed feelings about it. One of the results of this political game was that newspapers, politicians, scholars, and laypersons started to speak out more courageously. Al Jazeera has served as one of the primary fora for all types of political debate, and an even greater interest has been shown in it as a source of news.

Third, the wars on Afghanistan and later on Iraq added fuel to an area already on fire, as hinted at above.

Fourth, people started to feel that politics directly affects their daily lives and economic needs. For these reasons and others, both $\mathrm{Al}$ Jazeera and its online community seem to be more interested in the three categories of 'politics,' 'military and political violence,' and 'foreign relations.'

The fact that the three most frequent thematic news categories were offered in more salient positions in the news page may also have affected comments' rates. The site in this way may be seen as having a somewhat deterministic impact on commenters' choices of thematic categories.

\subsection{Regional Coverage}

The findings related to regional coverage show that readers showed a greater interest in commenting on the more frequent stories. In this way, the Arab world received not only the most frequent coverage of stories, but also the most frequent comments.
Interestingly, the percent comments on the Arab world exceeded that of stories covering the same region. The fact that $73 \%$ percent of the comments in the whole data targeted Arab world's issues probably shows that Al Jazeera Arabic's commenters are primarily visiting the site in order to read, and comment on, news related to that region, rather than elsewhere. The language of the news, i.e., Arabic, also plays an important and decisive factor in the frequency of comments as to regional coverage: Readers who can comment in Arabic are most likely native speakers of the language who are interested in the region's events more than those of other regions.

Similarly, the more frequent stories covering regions other than the Arab world received more frequent comments. This was the case for stories focusing on second world as well as the non-Arab non-Muslim world. These findings show that either Al Jazeera tries to cover stories based on prior knowledge on the part of $\mathrm{Al}$ Jazeera that such stories will be interesting to its readers or that readers are affected by the pattern of coverage Al Jazeera is offering and thus developed a pattern of commenting that correlates to that of Al Jazeera's story coverage.

\section{Conclusion}

The goal of the current study was to identify the extent and patterns of interactivity in news sites via comments on the top stories presented in such sites through the example of Al Jazeera. Al Jazeera's readers have actively participated in the news making process by actively commenting on the top stories. A strong correspondence was found between the categories as well as the regional coverage of the news offered and the rates of comments by readers. Al Jazeera was found to be a place where military and political violence, politics, and foreign relations are prioritized both by the site owners and the commenters. In addition, Al Jazeera as well as its commenters have been found to cover the Arab world more than the non-Arab world, and the second and third worlds more than the first world. Overall, these findings suggest that Journalism 2.0 on Al Jazeera tends to be shaped by the coverage and layout of the 
news site. Moreover, citizen participation in online news sites such as Al Jazeera is still far from ideal, in that commenters are given neither the access nor the facilitation to use modalities other than written text.

While the ways news stories are arranged in the news page have been found to affect patterns of comments, it may also be useful to interview readers/commenters about their potential commenting rates and whether or not such rates may be affected by layout and design of news sites. Further research is also needed to target the specific contents of the comments and to uncover the ideologies reflected in them. Studying patterns of interactional coherence and other linguistic features of the comments could also increase our knowledge of this new form of convergent media CMC. The demographics of commenters would also constitute an interesting area for future investigation, along with a comparative analysis of comments in English on news sites that provide both English and Arabic versions.

\section{References}

Abdul-Mageed, M. \& Herring, S. (2008). Arabic and English news coverage on aljazeera.net. In F. Sudweeks \& H. Hrachovec \& C. Ess (Eds.), Proceedings of Cultural Attitudes Towards Technology and Communication 2008 (CATaC'08), Nimes, France, June 24-27. Retrieved March 15, 2008, from reprint URL: http://ella.slis.indiana.edu/ herring/catac08.aljazeera.pdf

Auter, P. \& Arafa, M. \& Al-Jaber, K. (2004). Who Is Al Jazeera's Audience? Deconstructing the Demographics and Psychographics of an Arab Satellite News Network. Transnational Broadcasting Studies. Vol. 12. Retrieved July 20, 2007, from http://www.tbsjournal.com/html12/auter.htm

Barkho, L. (2006). The Arabic Al Jazeera Vs Britain's BBC and America's CNN: Who Does Journalism Right? In: American Communication Journal, 8(1), pp. 1-15.

Bauer, M. (2000). Classical content analysis: A review. In M. Bauer \& G. Gaskell (Eds.), Qualitative Researching with Text, Image and Sound (pp. 131-151). Thousand Oaks, CA: Sage.

Bowman, S. \& Willis, C. (2002). We Media: How Audiences Are Shaping the Future of News and Information. Reston, Va.: The Media Center at the American Press Institute, 2003. Retrieved November 5, 2006, from http://www.hypergene.net/wemedia/download/we media.pdf

Briggs, M. (2007). Journalism 2.0: How to Survive and Thrive. University of Maryland Philip Merrill College of Journalism and the Knight Citizen News Network. Retrieved March 4, 2008, from http://www.j-lab.org/Journalism 20.pdf

Deuze, M. (2001). Understanding the Impact of the Internet: On New Media Professionalism, Mindsets and Buzzwords. EJournalist, 1(1). Retrieved November 11, 2007, from http://www.ejournalism.au.com/ejournalist/deuze.pdf

Deuze, M. (2003). The Web and its journalisms: Considering the consequences of different types of news media online. New Media \& Society, 5(2), pp. 203-230.

Deuze, M. \& Bruns, A. \& Neuberger, C. (2007). Preparing for an Age of Participatory News. Journalism Practice, 1(3), pp. 322-338.

Dimitrova, D. \& Connolly-Ahern, C. (2006). A Tale of Two Wars: Framing Analysis of Online News Sites in Coalition Countries and the Arab World. The Howard Journal of Communications, 18, pp.153-168.

Ghareeb, E. (2000). New Media and the Information Revolution in the Arab World: An Assessment. The Middle East Journal, 54(3), pp. 395-418.

Herring, S. (2004). Content analysis for new media: Rethinking the paradigm. In New Research for New Media: Innovative Research Methodologies Symposium Working Papers and Readings (pp. 47-66). Minneapolis, MN: University of Minnesota School of Journalism and Mass Communication. Retrieved October 7, 2007, from http://ella.slis.indiana.edu/ herring/newmedia.pdf

Herring, S. (2008a). Virtual community. In L. Given (Ed.), Encyclopedia of Qualitative Research Methods. Thousand Oaks, CA: Sage. Retrieved November 10, 2007, from reprint URL http://ella.slis.indiana.edu/ herring/vc.pdf

Herring, S. (In press, 2008b). Web content analysis: Expanding the paradigm. In J. Hunsinger, M. Allen, \& L. Klastrup (Eds.), The International Handbook of Internet Research. Springer Verlag. Retrieved August 9, 2008, from reprint URL http://cat.slis.indiana.edu/ herring/webca.2008.pdf

Jarvis, J. (2006, July 5). Networked Journalism. Retrieved July 27, 2007, from http://www.buzzmachine.com/2006/07/05/networked-journalism/

Jensen, J. (1998). Interactivity: Tracking a new concept in media and communication studies. Nordicom Review, 1, pp. 185204.

Kutz, D. \& Herring, S. (2005). Micro-longitudinal analysis of Web news updates. Proceedings of the Thirty-Eighth Hawai'i International Conference on System Sciences (HICSS-38). Los Alamitos: IEEE Press. Retrieved August 20, 2007, from http://ella.slis.indiana.edu/ herring/news.pdf 
Murphy, J. \& Hofacker, C. \& Mizerski, R. (2006). Primacy and Recency Effects on Clicking Behavior. Journal of ComputerMediated Communication, 11(2). Retrieved October 23, 2007, from http://jcmc.indiana.edu/vol11/issue2/murphy.html

O'Reilly, T. (2005, October 1). Web 2.0: Compact Definition. O'Reilly Radar. Retrieved December 7, 2007, from http://radar.oreilly.com/archives/2005/10/web 20 compact definition.html

Rafaeli, S. (1988). Interactivity: From new media to communication. In R. Hawkins \& J. Wiemann \& S. Pingree (Eds.), Sage Annual Review of Communication Research: Advancing Communication Science: Merging Mass and Interpersonal Processes, 16, pp. 110-134.

Rafaeli, S. \& Sudweeks, F. (1997). Networked interactivity. Journal of Computer-Mediated Communication, 2(4). Retrieved October 23, 2007, from http://jcmc.huji.ac.il/vol2/issue4/rafaeli.sudweeks.html

Rich, C. (2003). Writing and Reporting News: A coaching method ( $4^{\text {th }}$ ed.). Wadsworth.

Schultz, T. (1999). Interactive Options in Online Journalism: a Content Analysis of 100 U.S. Newspapers . Journal of Computer-Mediated Communication, 5(1). Retrieved August 20, 2007, from http://www.ascusc.org/jcmc/vol5/issue1/schultz.html

Schultz, T. (2000). Mass media and the concept of interactivity: An exploratory study of online forums and reader e-mail. Media, Culture \& Society, 22(2), pp. 205-221.

Fry, S. (n.d.). Web 2.0 (Video interview). Retrieved November 7, 2007, from http://www.videojug.com/interview/stephen-fryweb-20

Seib, P. (2005). Hegemonic No More: Western Media, the Rise of Al-Jazeera, and the Influence of Diverse voices. International Studies Review, 7, pp. 601-615.

van Dijk, T. (1988). News Analysis: Case Studies of International and National News in the Press. Hillsdale, NJ: Erlbaum.

Whitaker, B. (2003, February 7). Battle Station. Guardian. Retrieved November 20, 2007, from http://www.guardian.co.uk/Archive/Article/0,4273,4600510,00.html

Wikipedia (2007, November 21). Al Jazeera. Retrieved November 21, 2007, from http://en. wikipedia.org/w/index.php?title=Al Jazeera\&oldid=172991637.

Zayani, M. (Ed.) (2005). The Al Jazeera Phenomenon: Critical Perspectives on New Arab Media. London: Pluto Press.

\section{About the Author}

Muhammad Abdul-Mageed is a Ph.D. student in the Dept. of Linguistics, Indiana University, Bloomington, USA. He is pursuing a Ph.D. major in computational linguistics and a minor in information science. He is specifically interested in computer-mediated communication as well as critical and corpus linguistics. His recent research has focused on online news sites (with a focus on Al Jazeera), video-sharing social network sites (with a focus on YouTube), and e-science (with a focus on Wikipedia). For more information about Muhammad and his research, visit his blog at: www.mumageed.blogspot.com 